\title{
ANALISIS CREEP TERHADAP MATERIAL PENGISI LUMPUR YANG DIGUNAKAN DI KAWASAN REKLAMASI
}

\author{
Max Suyatno Samsir ${ }^{1}$ dan Chaidir Anwar Makarim ${ }^{2}$ \\ ${ }^{1}$ Program Studi Sarjana Teknik Sipil, Universitas Tarumanagara, Jl. Letjen S. Parman No.1 Jakarta \\ Email: maxsamsir4@gmail.com \\ ${ }^{2}$ Program Studi Sarjana Teknik Sipil, Universitas Tarumanagara, Jl. Letjen S. Parman No.1 Jakarta \\ Email: chaidir259@gmail.com
}

\begin{abstract}
ABSTRAK
Reklamasi daratan adalah proses pembuatan daratan baru dari dasar laut dengan cara menimbun areal reklamasi tersebut dengan menggunakan material pengisi. Material pengisi tersebut dapat berupa batu, pasir bahkan lumpur. Penggunaan lumpur sebagai materal pengisi dapat dikatakan kontroversial mengingat lumpur dapat mengalami konsolidasi primer dan sekunder. Konsolidasi sekunder atau yang biasa disebut creep, adalah penurunan yang berjangka panjang dan berkemungkinan besarnya melebihi konsolidasi primer. Namun dalam realita, fenomena creep jarang sekali diperhitungkan oleh perencana. Penelitian ini bertujuan untuk membuktikan bahwa fenomena creep sangat penting untuk diperhitungkan. Untuk menganalisisnya digunakan program dengan metode boussinesq. Penelitian ini dilakukan dengan menghitung besar creep yang terjadi pada material pengisi lumpur dengan menggunakan embankment load dengan tinggi yang berbeda. Simulasi ini menunjukkan bahwa creep sangat penting untuk diperhitungkan.
\end{abstract}

Kata kunci: reklamasi daratan, lumpur, konsolidasi, creep, boussinesq

\section{PENDAHULUAN}

\section{Latar Belakang}

Adanya kebutuhan manusia untuk menciptakan lahan yang digunakan untuk berbagai macam aktifitas meningkat seiring dengan berjalannya waktu serta pembangunan, namun lahan yang dapat langsung dikembangkan bisa jadi tidak mencukupi peningkatan kebutuhan tersebut. Salah satu cara untuk dapat mengubah lahan yang tidak layak digunakan tersebut menjadi layak adalah dengan mengadakan reklamasi.

Menurut Suharto (2018), reklamasi adalah suatu pekerjaan/usaha memanfaatkan kawasan atau lahan yang relatif tidak berguna atau masih kosong dan berair menjadi lahan berguna dengan cara dikeringkan. Pada dasarnya reklamasi merupakan kegiatan yang mengubah wilayah perairan pantai menjadi daratan yang dimaksudkan untuk mengubah permukaan tanah yang rendah (biasanya terpengaruh oleh genangan air) menjadi lebih tinggi (biasanya tidak terpengaruh genangan air).

Menurut Wagiu, (2011), ditinjau dari aspek fisik dan lingkungannya, tujuan reklamasi yaitu:

1. Untuk mengembalikan tanah yang hilang akibat gelombang laut.

2. Untuk mengembalikan tanah baru di Kawasan depan garis pantai untuk mendirikan bangunan yang nantinya difungsikan sebagai benteng perlindungan garis pantai.

3. Untuk alasan ekonomis, pembangunan atau untuk mendirikan konstruksi bangunan dalam skala yang lebih besar.

Namun dalam pelaksanaannya, sering terjadi permasalahan khususnya permasalahan geoteknik di lokasi diadakannya reklamasi tersebut. Salah satunya adalah creep atau yang biasa disebut dengan rangkak. Menurut Bowless dan Hainim (1991), creep adalah suatu kondisi dimana tanah mengalami penurunan tanpa adanya perubahan beban. Kondisi ini sama dengan secondary settlement atau secondary consolidation, yang berlanjut setelah primary consolidation.

Melalui studi ini, akan dianalisa besarnya potensi creep pada material pengisi yang dapat terjadi di suatu proyek reklamasi. Sehingga dapat diketahui seberapa besar dan berbahaya potensi creep material pengisi yang akan terjadi di proyek reklamasi tersebut. 


\section{Tujuan}

Tujuan dari penelitian ini adalah mengetahui besarnya creep terhadap material pengisi lumpur di sebuah proyek reklamasi menggunakan program berbasis boussinesq dalam kurun waktu 100 tahun dengan pemodelan embankment load setinggi $1 \mathrm{~m}, 1.5 \mathrm{~m}$ dan $2 \mathrm{~m}$.

\section{CREEP PADA TANAH}

Menurut Braja M. Das (1995), creep (biasa disebut secondary consolidation atau secondary compression) adalah penurunan yang berlanjut setelah konsolidasi primer. Penurunan ini terjadi seiring dengan waktu berlalu dan biasanya terjadi sangat lama setelah beban mulai bekerja, di mana partikel tanah mengalami creep. Penurunan ini terjadi saat semua tegangan air pori berlebih di dalam tanah telah terdisipasi dan saat tegangan efektif yang terjadi berada dalam keadaan konstan. Menurut Budhu dan Bowles (2015), creep terjadi pada tegangan efektif yang konstan, yaitu setelah penurunan konsolidasi primer berhenti.

Menurut Wesley (1997), besar penurunannya merupakan fungsi waktu (t) dan kemiringan kurva indeks pemampatan sekunder $(C \alpha)$. Penurunan akibat konsolidasi sekunder, dihitung dengan persamaan:

$$
S_{s}=\frac{C \alpha}{1+e_{p}} H \log \frac{t_{2}}{t_{1}}
$$

dengan $C_{\alpha}=$ indeks pemampatan sekunder, $e_{p}=$ angka pori saat akhir konsolidasi primer, $H=$ tebal lapisan lempung dan $t_{2}=$ waktu setelah konsolidasi primer berhenti.

\section{PEMODELAN PROGRAM}

\section{Input Data}

Berdasarkan hasil uji laboratorium, lapangan dan korelasi, dapat dianalisis untuk mendapatkan parameter-parameter yang akan digunakan untuk melakukan pemodelan. Data didapat dari proyek di wilayah Jakarta namun tidak diperbolehkan untuk dipublikasi. Berikut merupakan kesimpulan parameter yang digunakan untuk pemodelan creep dengan menggunakan program berbasis boussinesq yang dapat dilihat pada tabel 1 sebagai berikut.

Tabel 1. Parameter Tanah yang Digunakan (Data Proyek di Wilayah Jakarta)

\begin{tabular}{lccc}
\hline \multicolumn{1}{c}{ Parameter } & $\begin{array}{c}\text { Upper } \\
\text { Holocene Clay }\end{array}$ & $\begin{array}{c}\text { Lower } \\
\text { Holocene Clay }\end{array}$ & $\begin{array}{c}\text { Cutter Suction } \\
\text { Dredged Mud }\end{array}$ \\
\hline$\gamma-$ Unit Weight $\left(\mathrm{kN} / \mathrm{m}^{2}\right)$ & 14.3 & 14.6 & 12 \\
\hline$\gamma_{\text {sat }}-$ Sat. Unit Weight $\left(\mathrm{kN} / \mathrm{m}^{2}\right)$ & 16.3 & 16.3 & 14 \\
\hline$v-$ Poisson Ratio & 0.2 & 0.2 & 0.15 \\
\hline $\mathrm{Cc}-$ Compression Index & 0.96 & 0.85 & 1.08 \\
\hline $\mathrm{Cr}-$ Recompression Index & 0.146 & 0.108 & 0.18 \\
\hline $\mathrm{K}-$ Permeability $(\mathrm{m} / \mathrm{year})$ & 0.8979 & 0.22557 & 5.7305 \\
\hline $\mathrm{C} \alpha / \mathrm{C}_{\mathrm{c}}$ Ratio & 0.06 & 0.06 & 0.06 \\
\hline $\mathrm{e}_{\mathrm{o}}-$ Initial Void Ratio & 3 & 2.54 & 3.5 \\
\hline $\mathrm{OCR}-$ Over-Consolidation Ratio & 1 & 1 & 1 \\
\hline
\end{tabular}

Dalam pemodelannya, diperlukan ketebalan per lapisan tanah. Ketebalan per lapisan tanah dapat dilihat pada tabel 3 sebagai berikut.

Tabel 2. Ketebalan Lapisan Tanah (Data Proyek di Wilayah Jakarta)

\begin{tabular}{ccc}
\hline & Jenis Material & Kedalaman \\
\hline Lapisan 1 & Cutter Suction Dredged Mud & $30 \mathrm{~m}$ \\
\hline Lapisan 2 & Upper Holocene Clay & $25 \mathrm{~m}$ \\
\hline Lapisan 3 & Lower Holocene Clay & $45 \mathrm{~m}$ \\
\hline
\end{tabular}

Karena analisis dilakukan dengan kurun waktu 100 tahun, maka stage per year harus dikonfigurasikan pada program tersebut. Konfigurasi tahun yang digunakan dapat dilihat pada gambar 1 sebagai berikut. 


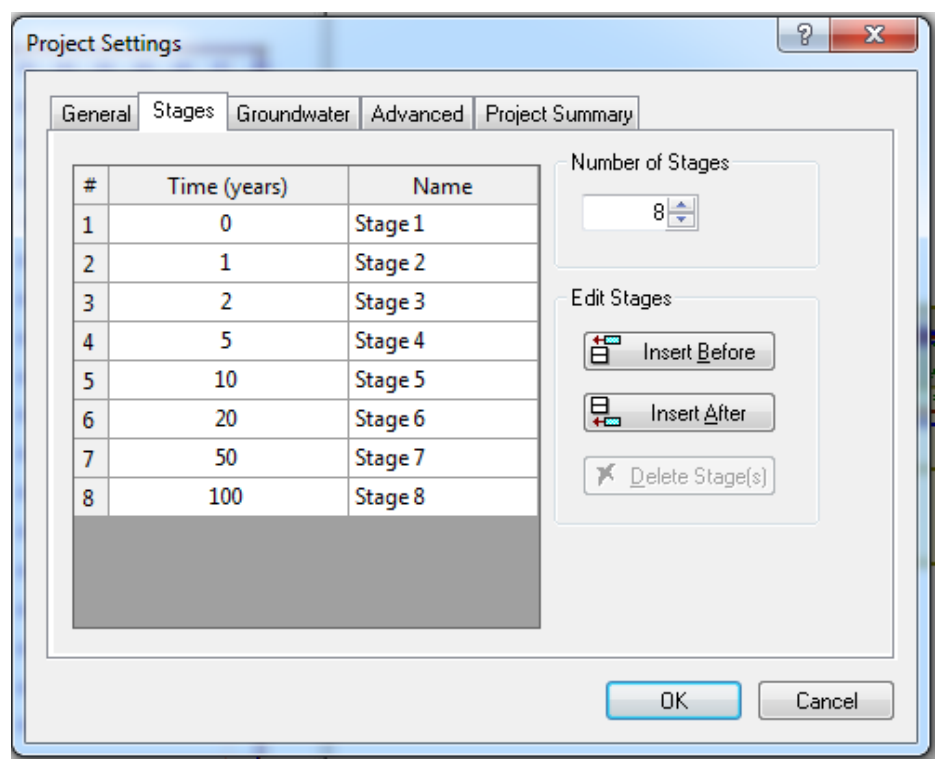

Gambar 1. Konfigurasi Tahun yang Digunakan

Dalam pemodelan digunakan pula wick drain. Wick drain digunakan untuk mempercepat rate of settlement agar konsolidasi berjalan lebih cepat. Spesifikasi wick drain didapat dari data proyek di wilayah Jakarta namun tidak diperbolehkan untuk dipublikasi. Spesifikasi wick drain yang digunakan dapat dilihat pada tabel 3 sebagai berikut.

Tabel 3. Spesifikasi Wick Drain yang Digunakan (Data Proyek di Wilayah Jakarta)

\begin{tabular}{ll}
\hline Installation Stage & $0=0 \mathrm{y}$ \\
\hline Cross Section Shape & Strip \\
\hline Width & $0.1 \mathrm{~m}$ \\
\hline Thickness & $0.005 \mathrm{~m}$ \\
\hline Drain spacing & $1.2 \mathrm{~m}$ \\
\hline Drain length & $20 \mathrm{~m}$ \\
\hline Drain pattern & Square \\
\hline Ratio of diameter of smear zone to diameter of drain & 1 \\
\hline Ratio of undistributed to smear zone permeability & 1 \\
\hline Double drainage & Yes \\
\hline Discharge capacity & $10 \mathrm{~m}^{3} /$ year $=0.833 \mathrm{~m}^{3} / \mathrm{month}$ \\
\hline
\end{tabular}

Dalam pemodelan embankment load, akan digunakan tinggi dengan variasi $1 \mathrm{~m}, 1.5 \mathrm{~m}$ dan $2 \mathrm{~m}$. Embankment load dimodelkan menjadi jenis tanah pasir dengan berat jenis sebesar $16.2 \mathrm{kN} / \mathrm{m}^{3}$ dalam pemodelannya. 


\section{Pemodelan Creep dengan Embankment Load Setinggi 1 m}

Berdasarkan hasil parameter yang sudah ditentukan, akan dilakukan input ke program berbasis boussinesq. Hasil pemodelan dapat dilihat pada gambar dan tabel berikut ini.

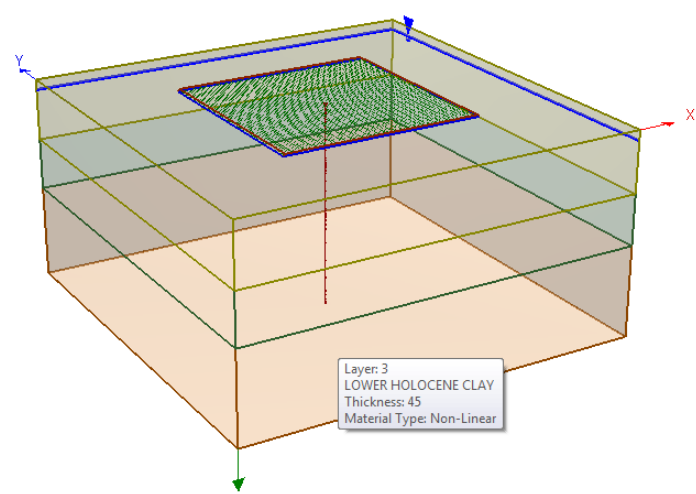

Gambar 2. Pemodelan Analisis Pertama dalam Bentuk 3D

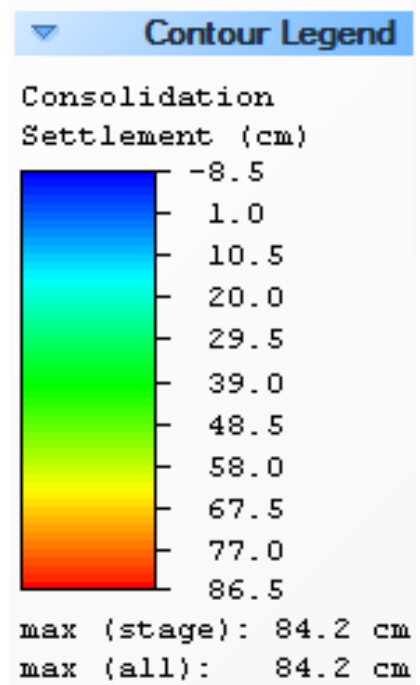

Gambar 3. Total Consolidation Settlement pada Analisis Pertama

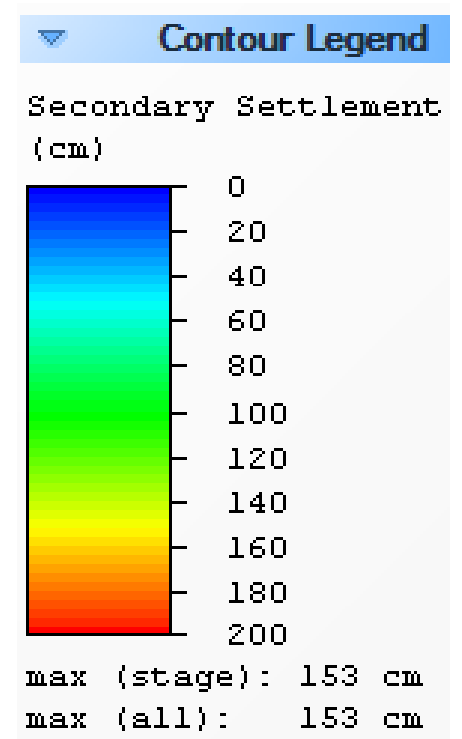

Gambar 4. Total Secondary Settlement pada Analisis Pertama 
Tabel 4. Secondary Settlement per Tahun pada Analisis Pertama

\begin{tabular}{cc}
\hline Time $(\mathrm{y})$ & Secondary Settlement $(\mathrm{cm})$ \\
\hline 0 & 0 \\
\hline 1 & 0 \\
\hline 1.35221 & 4.40469 \\
\hline 2 & 11.7041 \\
\hline 5 & 30.3809 \\
\hline 10 & 46.3216 \\
\hline 20 & 67.0563 \\
\hline 50 & 109.801 \\
\hline 100 & 153.347 \\
\hline
\end{tabular}

Time vs. Secondary Settlement

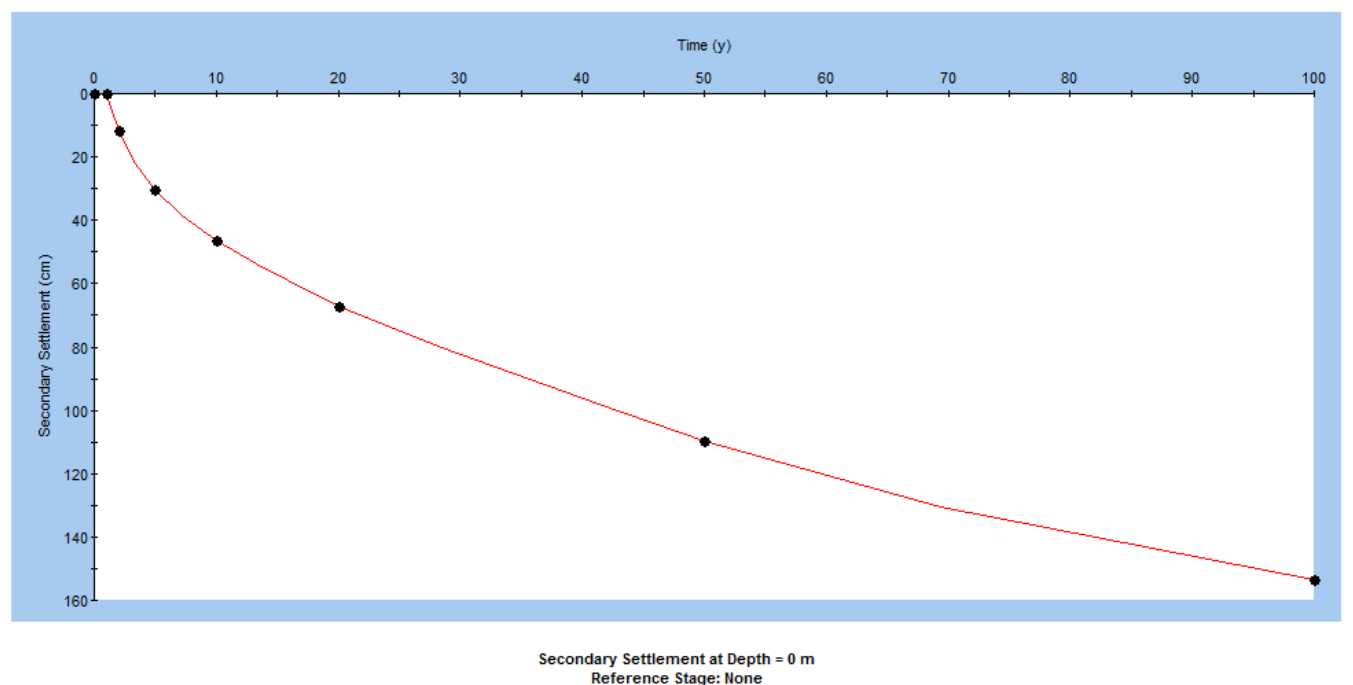

Gambar 5. Grafik Time vs. Secondary Settlement pada Analisis Pertama

\section{Pemodelan Creep dengan Embankment Load Setinggi $1.5 \mathrm{~m}$}

Dengan parameter yang sama, tinggi embankment load divariasikan menjadi $1.5 \mathrm{~m}$, kemudian akan dilakukan input ke program berbasis boussinesq. Hasil pemodelan dapat dilihat pada gambar berikut ini.

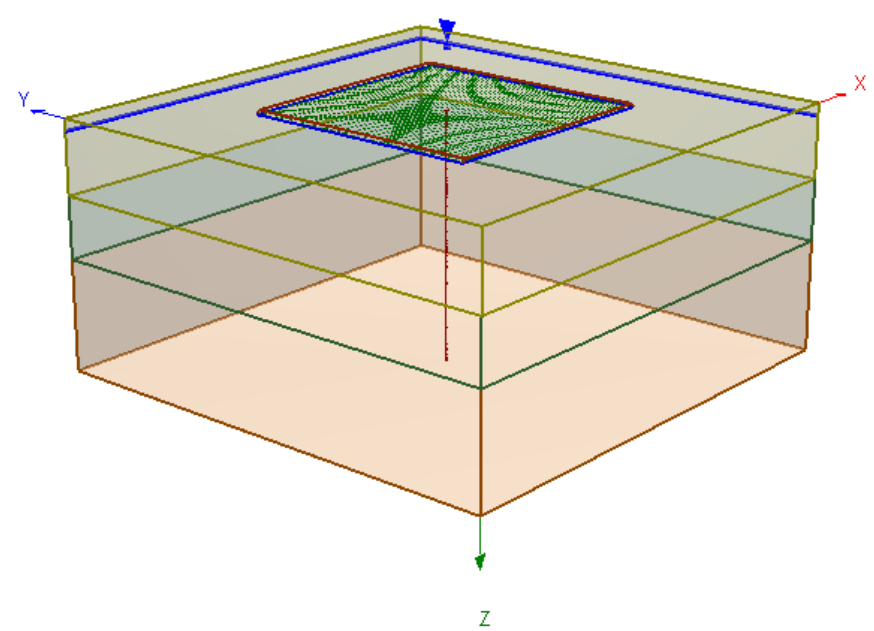

Gambar 6. Pemodelan Analisis Kedua dalam Bentuk 3D 


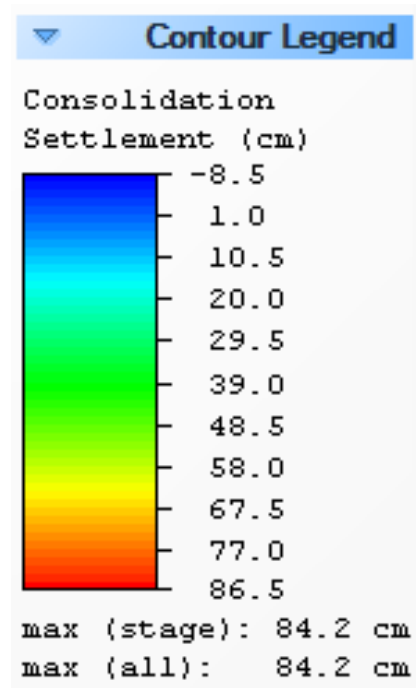

Gambar 7. Total Consolidation Settlement pada Analisis Kedua

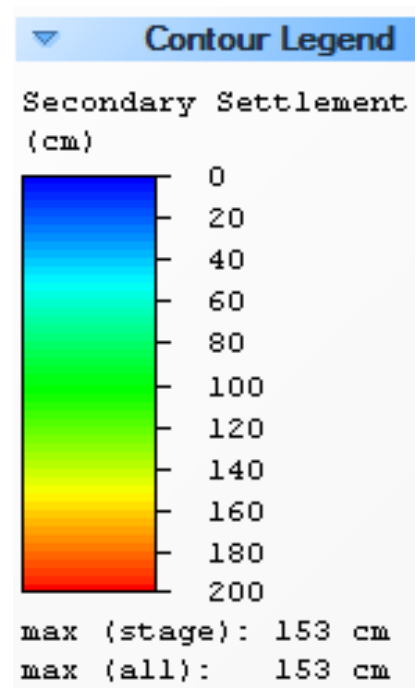

Gambar 8. Total Secondary Settlement pada Analisis Kedua

Tabel 5. Secondary Settlement per Tahun pada Analisis Kedua

\begin{tabular}{cc}
\hline Time $(\mathrm{y})$ & \multicolumn{2}{c}{ Secondary Settlement $(\mathrm{cm})$} \\
\hline 0 & 0 \\
\hline 1 & 0 \\
\hline 1.35221 & 4.44812 \\
\hline 2 & 11.8118 \\
\hline 5 & 30.6444 \\
\hline 10 & 46.7085 \\
\hline 20 & 67.5772 \\
\hline 50 & 110.592 \\
\hline 100 & 154.492 \\
\hline
\end{tabular}


Time vs. Secondary Settlement

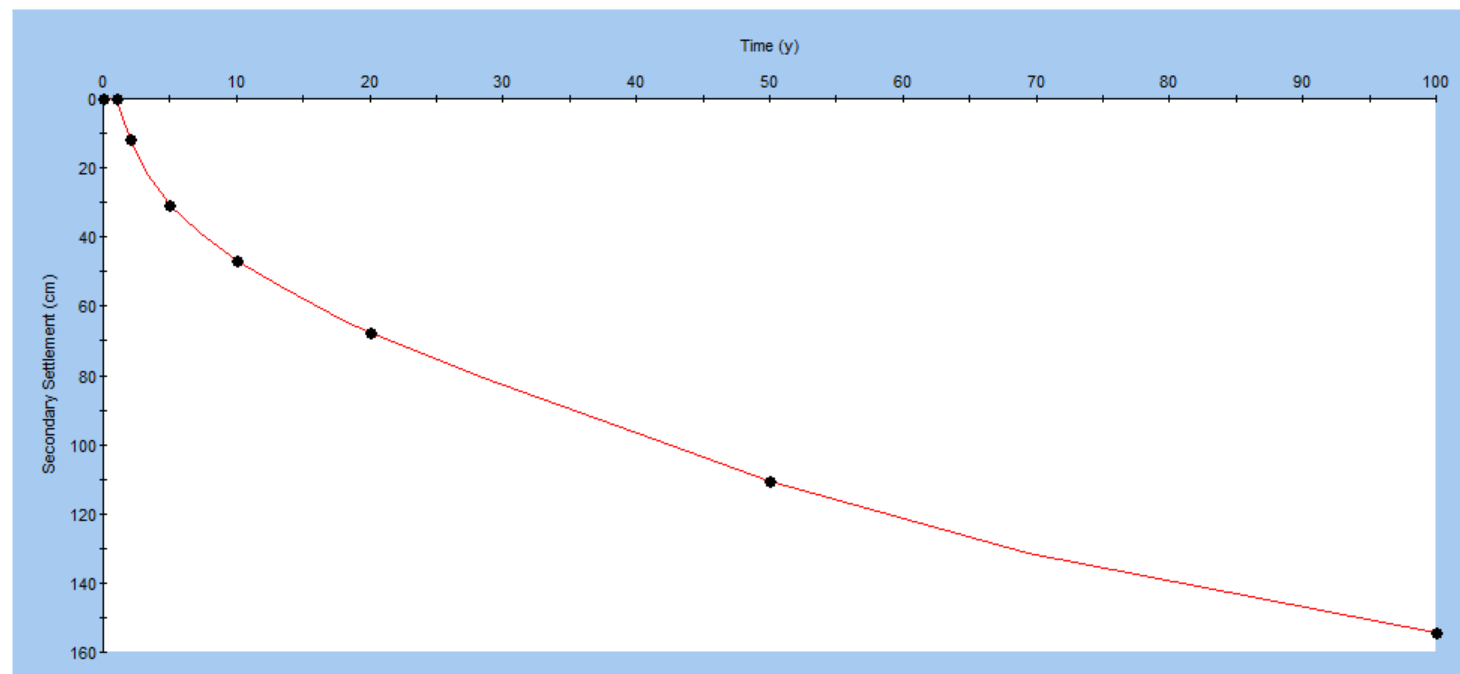

Secondary Settlement at Depth $=0 \mathrm{~m}$

Gambar 9. Grafik Time vs. Secondary Settlement pada Analisis Kedua

Apabila dibandingkan dengan hasil analisis pertama, dapat dilihat dari hasil analisis kedua bahwa besar consolidation settlement yang didapatkan adalah sebesar $118 \mathrm{~cm}$ dan besar secondary settlement yang didapatkan adalah sebesar $154.492 \mathrm{~cm}$ dalam kurun waktu 100 tahun. Besar secondary settlement mengalami peningkatan yang tidak terlalu signifikan.

\section{Pemodelan Creep dengan Embankment Load Setinggi 2 m}

Dengan parameter yang sama, tinggi embankment load divariasikan menjadi $2 \mathrm{~m}$, kemudian akan dilakukan input ke program berbasis boussinesq. Hasil pemodelan dapat dilihat pada gambar berikut ini.

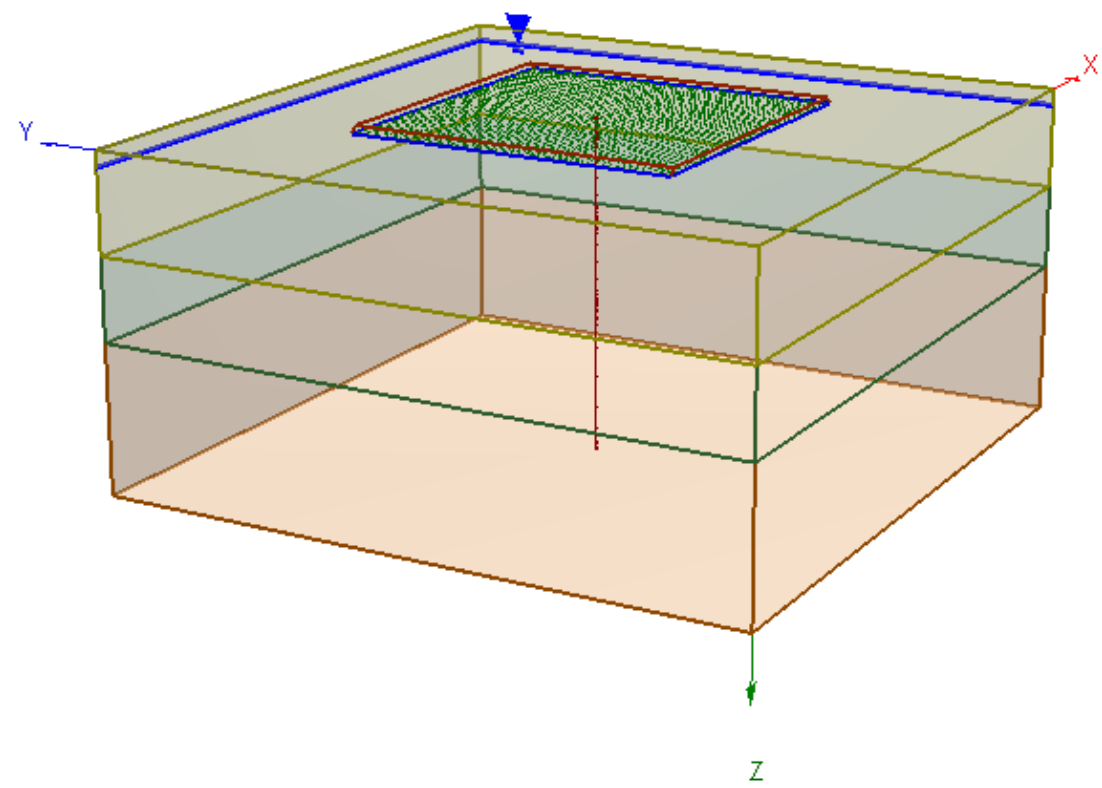

Gambar 10. Pemodelan Analisis Ketiga dalam Bentuk 3D 


\section{$\nabla \quad$ Contour Legend}

Consolidation

Settlement (cm)

$-8.5$

1.0

10.5

20.0

$-29.5$

39.0
$-\quad 48.5$

$\begin{array}{r}-48.5 \\ \hline\end{array}$

$-58.0$

67.5

77.0

86.5

max (stage): $84.2 \mathrm{~cm}$

max (all): $84.2 \mathrm{~cm}$

Gambar 11. Total Consolidation Settlement pada Analisis Ketiga
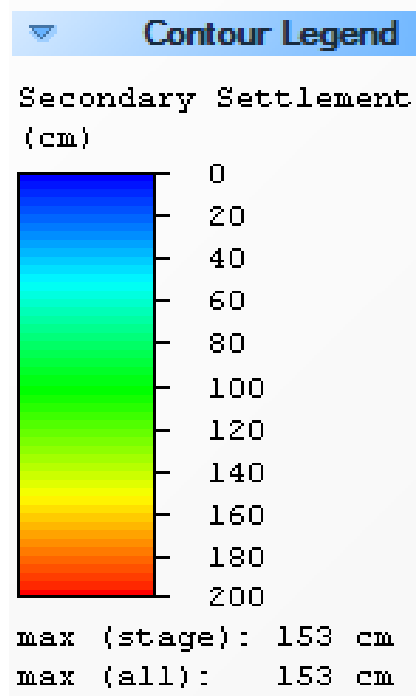

Gambar 12. Total Secondary Settlement pada Analisis Ketiga

Tabel 13. Secondary Settlement per Tahun pada Analisis Ketiga

\begin{tabular}{cc}
\hline Time $(\mathrm{y})$ & Secondary Settlement $(\mathrm{cm})$ \\
\hline 0 & 0 \\
\hline 1 & 0 \\
\hline 1.352211 & 4.48746 \\
\hline 2 & 11.9109 \\
\hline 5 & 30.8909 \\
\hline 10 & 47.0677 \\
\hline 20 & 68.0605 \\
\hline 50 & 111.258 \\
\hline 100 & 155.307 \\
\hline
\end{tabular}




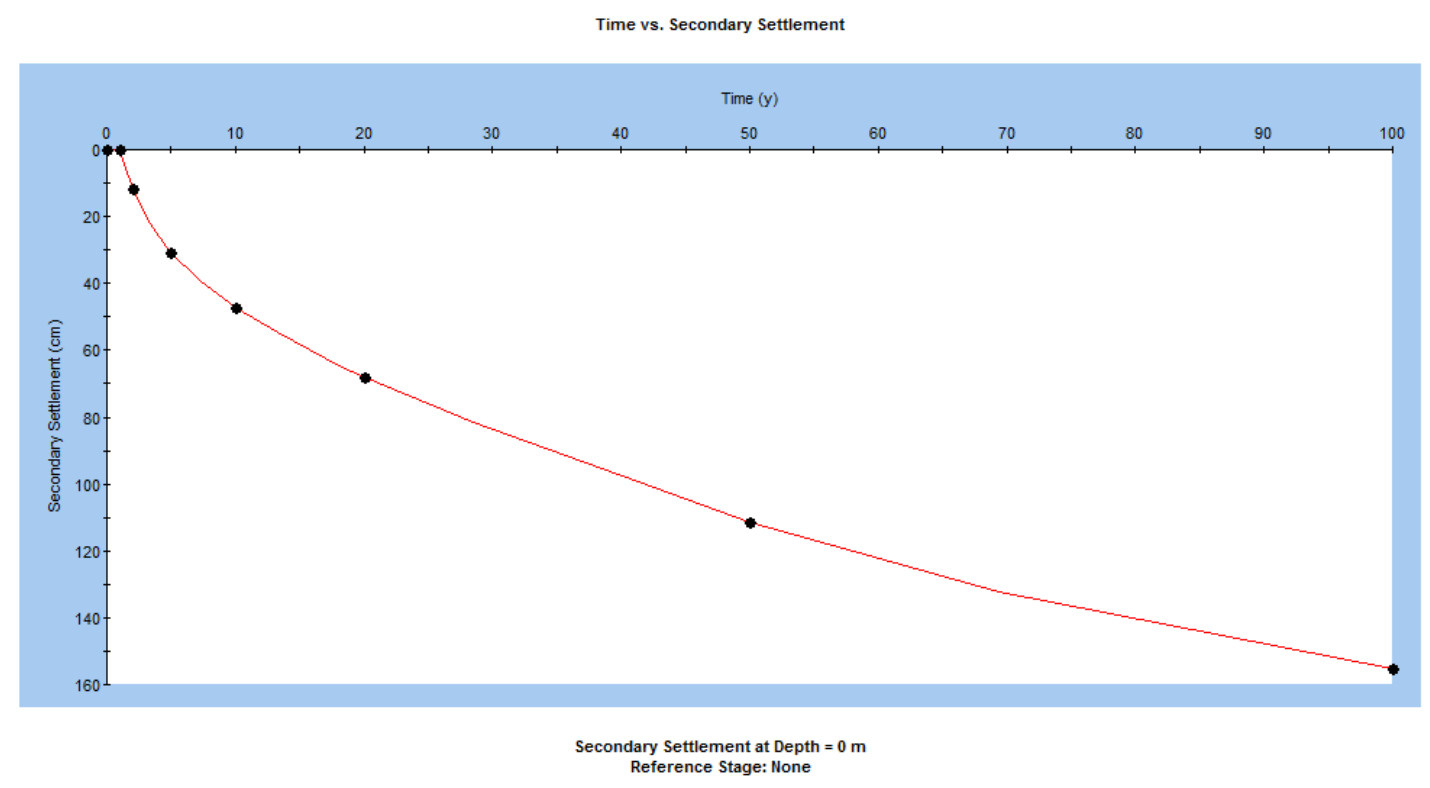

Gambar 10. Grafik Time vs. Secondary Settlement pada Analisis Ketiga

Apabila dibandingkan dengan hasil analisis kedua, dapat dilihat dari hasil analisis ketiga bahwa besar consolidation settlement yang didapatkan adalah sebesar $149 \mathrm{~cm}$ dan besar secondary settlement yang didapatkan adalah sebesar $155.307 \mathrm{~cm}$ dalam kurun waktu 100 tahun. Besar secondary settlement mengalami peningkatan seperti sebelumnya namun tidak terlalu signifikan.

\section{KESIMPULAN}

Berdasarkan analisis yang dilakukan menggunakan program berbasis boussinesq, didapatkan beberapa kesimpulan sebagai berikut:

1. Dari hasil analisis dengan program Settle $3 D$ terhadap material pengisi lumpur, dalam kurun waktu 100 tahun dengan menggunakan embankment load berupa pasir setinggi $1 \mathrm{~m}$ didapatkan secondary settlement sebesar $153.347 \mathrm{~cm}$. Dengan memvariasikan tinggi embankment load menjadi sebesar $1.5 \mathrm{~m}$ dan $2 \mathrm{~m}$, didapatkan secondary settlement sebesar $154.492 \mathrm{~cm}$ dan $155.307 \mathrm{~cm}$. Dari hasil tersebut, dapat disimpulkan bahwa penambahan tinggi embankment load tidak terlalu mempengaruhi besarnya secondary settlement.

2. Dari hasil grafik time vs. secondary settlement, dapat disimpulkan bahwa menggunakan material pengisi berupa cutter suction dredged mud dapat mengakibatkan secondary settlement yang cukup besar dalam kurun waktu 100 tahun.

3. Dari hasil perbandingan antara consolidation settlement dengan secondary settlement dalam kurun waktu 100 tahun, didapatkan hasil secondary settlement lebih besar daripada consolidation settlement. Sehingga, dapat disimpulkan bahwa dalam merencanakan konstruksi di kawasan reklamasi dengan menggunakan material filler berupa cutter suction dredged mud, creep sangat penting untuk diperhitungkan

\section{DAFTAR PUSTAKA}

Bowless, J.E. and Hainim, J.K. (1991). Sifat-Sifat Fisis dan Geoteknis Tanah. Jakarta: Penerbit Erlangga Budhu, M. and J.E. Bowles (2015). Soil Parameters and Correlation. New York: John Wiley \& Sons Das, Braja M. (1995). Mekanika Tanah (Prinsip-Prinsip Rekayasa Geoteknis) Jilid 1. Jakarta: Penerbit Erlangga Das, Braja M. (2002). Mekanika Tanah (Prinsip-Prinsip Rekayasa Geoteknis) Jilid 2. Jakarta: Penerbit Erlangga Harwadi, Fuad. Teknik Reklamasi. Universitas Borneo, Tarakan Wesley, L.D. (1997). Mekanika Tanah. Jakarta: Badan Penerbit Pekerjaan Umum 
